\title{
LCC Resonant Multilevel Converter for X-ray Applications
}

\author{
A. M. Pernía * (D), Miguel J. Prieto (D), Pedro J. Villegas, Juan Díaz and Juan A. Martín-Ramos \\ Department of Electrical Engineering, University of Oviedo, 33203 Gijón, Asturias, Spain; \\ mike@uniovi.es (M.J.P.); pedroj@uniovi.es (P.J.V.); jdiazg@uniovi.es (J.D.); jamartin@uniovi.es (J.A.M.-R.) \\ * Correspondence: amartinp@uniovi.es; Tel.: +34-985-182-566
}

Academic Editor: Gabriele Grandi

Received: 25 July 2017; Accepted: 9 October 2017; Published: 12 October 2017

\begin{abstract}
Medical X-ray appliances use high-voltage power supplies that must be able to work with very different energy requirements. Two techniques can be distinguished in X-ray medical imaging: fluoroscopy and radioscopy. The former involves low power radiation with a long exposure time, while radioscopy requires large power during short radiographic exposure times. Since the converter has to be designed by taking into account the maximum power specification, it will exhibit a poor efficiency when operating at low power levels. Such a problem can be solved by using a new multilevel LCC topology. This topology is based on a classical series-parallel resonant topology, but includes an additional low-voltage auxiliary transformer whose function depends on the X-ray technique considered. When radioscopy operation is selected, the transformer will allow the power to be shared between two full-bridges. If fluoroscopy mode is activated, the auxiliary full bridge is disconnected and the magnetizing inductance of the auxiliary transformer is used to increase the resonant inductor in order to reduce the resonant currents, thus improving the efficiency of the converter.
\end{abstract}

Keywords: AC/DC converter; fluoroscopy; high voltage; multilevel; radioscopy; resonant conversion; X-ray

\section{Introduction}

Many industrial and medical applications (X-ray generation, electron beam welding, electrostatic precipitators [1-5]) need to generate high output voltages (as high as $200 \mathrm{kV}$ ) together with large power variations. In the case of X-ray applications, the power delivered to the X-ray tube usually varies widely $(<1 \mathrm{~kW}-100 \mathrm{~kW})$, depending, among others, on the radiographic technique used (fluoroscopy, radioscopy) or the material type and thickness. As far as voltage specifications are concerned, they range from $50 \mathrm{kV}$ to $150 \mathrm{kV}$ (Figure 1).

Not only do the electrical specifications represent a technological problem for the power stage that has to cope with such a wide power range: the design is also complicated by the tolerances in the power grid as defined by different $\mathrm{AC}$ grid regulations all around the world. Taking this into account, the DC input voltage for this power stage is set to have a value ranging from $V_{i}=400 \mathrm{~V}$ to $V_{i}=750 \mathrm{~V}$, which is suitable to be used with a three-phase rectifier.

Taking into account all of the conditions indicated above, it is necessary to select a topology that can deal with the variation ranges considered for the input voltage and for the output power, without affecting its performance. LCC resonant topology is commonly used for these applications (Figure 2) [6,7]. The steady state analysis of this converter has been previously introduced, as we can see in references [8-12]. Other specific design for optimal control, SiC (Silicon Carbide) rectifier modeling or small signal model are also presented in [13-19]. 


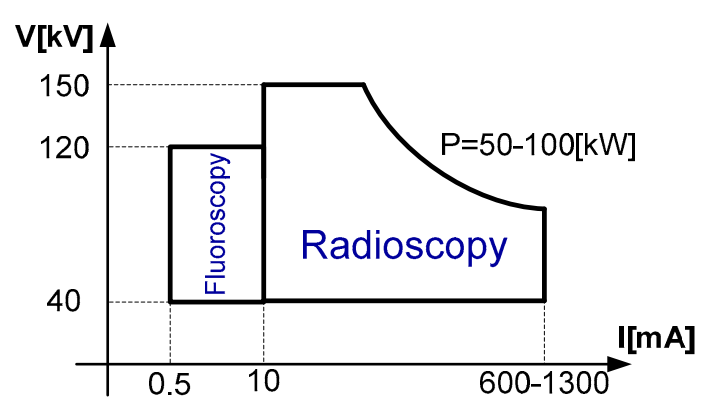

Figure 1. Output power and output voltage specifications for X-ray power supplies.

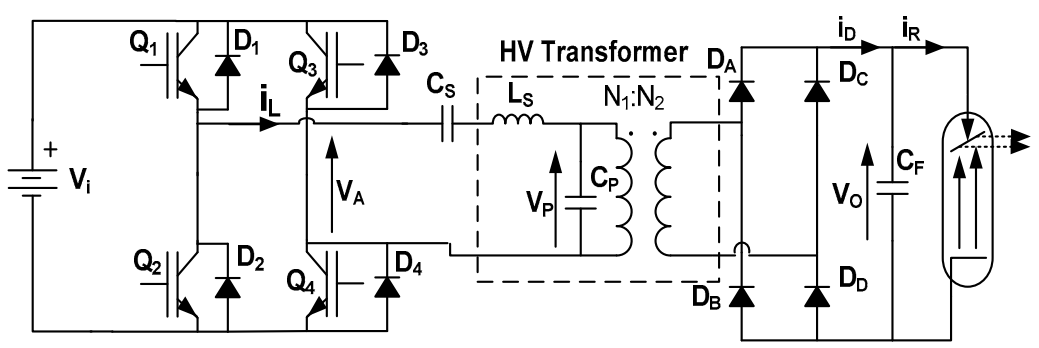

Figure 2. Series-parallel LCC resonant topology.

The fact of using resonant inductors and capacitors makes the LCC-PRC (Parallel Resonant Converter) specially suited for high-voltage DC power supplies and distributed DC/DC applications, where the transformer parasitic elements are usually incorporated into the basic operation of the whole circuit. Due to the high output voltage demanded, a high transformer ratio is required. The large number of turns in the secondary side of this transformer will determine the value of the parasitic capacitance in the topology. In a similar way, the leakage inductance will depend on the winding geometrical structure and the number of turns in the primary side. These parasitic elements will affect the converter operation, so including them in the power topology becomes mandatory; as mentioned above, the PRC-LCC converter fulfils this objective.

Compared to the series resonant converter or the parallel resonant converter, the LCC-PRC also exhibits better performance at output voltage regulation, and a better reliability with short-circuit or open-circuit condition [12-14]. Therefore, the LCC-PRC combines the good behaviour of SRC (Series Resonant Converter) under short-circuit with that of PRC at no load, thus being capable to operate with a wide output voltage and output power ranges. LLC resonant converter uses the magnetizing inductance as a resonant element trying to increase the power density, but it does not include the transformer parasitic capacitance in the resonant tank which is very important in high voltage applications due to the large value it exhibits. Burst mode operation is other interesting alternative for light load, and there are recent applications that use this alternative for controlling LLC converters $[20,21]$. However, this technique has also some drawbacks for the application presented in this paper.

The inclusion of a large dead time between each pulse, like that associated to burst-mode operation, involves a large low-frequency ripple in the output voltage, which, due to the higher harmonic content, could be audible. Additional low-pass-filter is required at the high-voltage side and also at the input of the converter to minimize EMI (electromagnetic interference) problems. During stand-by mode (period between burst pulses), a resonance appears between $L_{S}, C_{S}$, and $C_{P}$ with a current similar to the nominal one, which involves an important reactive energy in the converter. Also, if the stand-by period is too large, a new transient process appears in each burst pulse.

Appropriate design of the LCC-PRC converter is always made for the worst operating conditions (lowest input voltage, highest output power, and voltage); this is the way to guarantee that the converter specifications are met for any other operating point. When these worst-case conditions 
are considered, transferring the maximum power to the load while providing a high output voltage requires that a high parallel capacitance and a low series inductance be present in the circuit.

Once the LCC resonant tank is obtained considering these worst-case operating conditions (maximum output power), it must be guaranteed that the power topology can also work under low-power conditions (some tens of watts), while keeping the output voltage at values of hundreds of $\mathrm{kV}$. Since it is necessary to have a high resonant current in the topology in order to obtain the nominal output voltage and regardless of the power demanded, the converter efficiency will be penalized when operating under low-power conditions. This high resonant current is necessary to provide the voltage required across the parallel resonant capacitor in order for the topology to work properly. Note that the maximum value for this voltage does not depend on the power demanded: its value is determined by the output voltage only. Hence, Equation (1) shows how to calculate the value of the resonant current:

$$
I_{C p-\max }=V_{O-\max } \cdot \omega \cdot C_{P}
$$

Thus, the main drawback of the LCC topology appears because of the wide power range associated to X-ray applications. In this case, the efficiency at low power decreases dramatically, which makes it essential to adapt the LCC topology in such a way that it is possible to control the value of the resonant current as a function of the power being transferred to the load.

The goal of this paper is trying to overcome this problem by modifying the resonant inductor during fluoroscopy (low-power) operation. The proposed multilevel converter solves these problems by including an additional full bridge that can also contribute to increasing the maximum output power $(>100 \mathrm{~kW})$, which is the actual tendency in X-ray generators. In reference to [22], the basics of the converter operation were introduced. Reference [23] explains the basics of the converter operation again and includes experimental results at power scale 1:100. The present paper further illustrates the advantages of using a multilevel LCC converter in both operation modes (fluoroscopy and radioscopy) and includes new experimental results at nominal power; the tests performed show the important efficiency improvement achieved. Additionally, this work provides key rules (materials, structure, connections to power topology) for designing the high voltage transformer. Topics related to the output filter capacitor and voltage conversion ratio are also presented.

\section{Materials and Methods}

\subsection{Topology}

As already indicated, depending on the X-ray technique used, there are two different conditions that the multilevel must operate at. Each of these situations defines two different output specifications, whose nominal operation values are:

- Fluoroscopy: $1.2 \mathrm{~kW}-120 \mathrm{kV}$

- Radioscopy: $100 \mathrm{~kW}-150 \mathrm{kV}$

So, different power specifications may be covered by using a multilevel converter like that in Figure 3. In this topology, an auxiliary isolation transformer is used at the low-voltage side to connect in series two FB (full bridges). When needed, each full bridge will contribute with one half of the total power demanded by the load.

The utility of the auxiliary transformer is twofold. On the one hand, it allows the voltage across the resonant tank to be defined by varying the duty cycle of the two full bridges included in the topology. On the other hand, it can be used to increase the value of the resonant inductance when using the fluoroscopy technique. This increase of the resonant inductor is achieved by turning the slave bridge off, which results in the resonant inductance being the series association of the magnetizing inductance of the auxiliary transformer plus the leakage inductance of the high-voltage transformer of the main bridge. This new situation involves a specific design of the auxiliary transformer in order to avoid saturation during the fluoroscopy operation. 
During the radioscopy mode operation, both full-bridge converters are synchronized in such a way that the voltage generated by each one $\left(V_{A}, V_{B}\right)$ is reflected at the primary side of the HV (high voltage) transformer as $V_{A B}=V_{A}+V_{B}$ thanks to the isolation that introduces the auxiliary transformer.

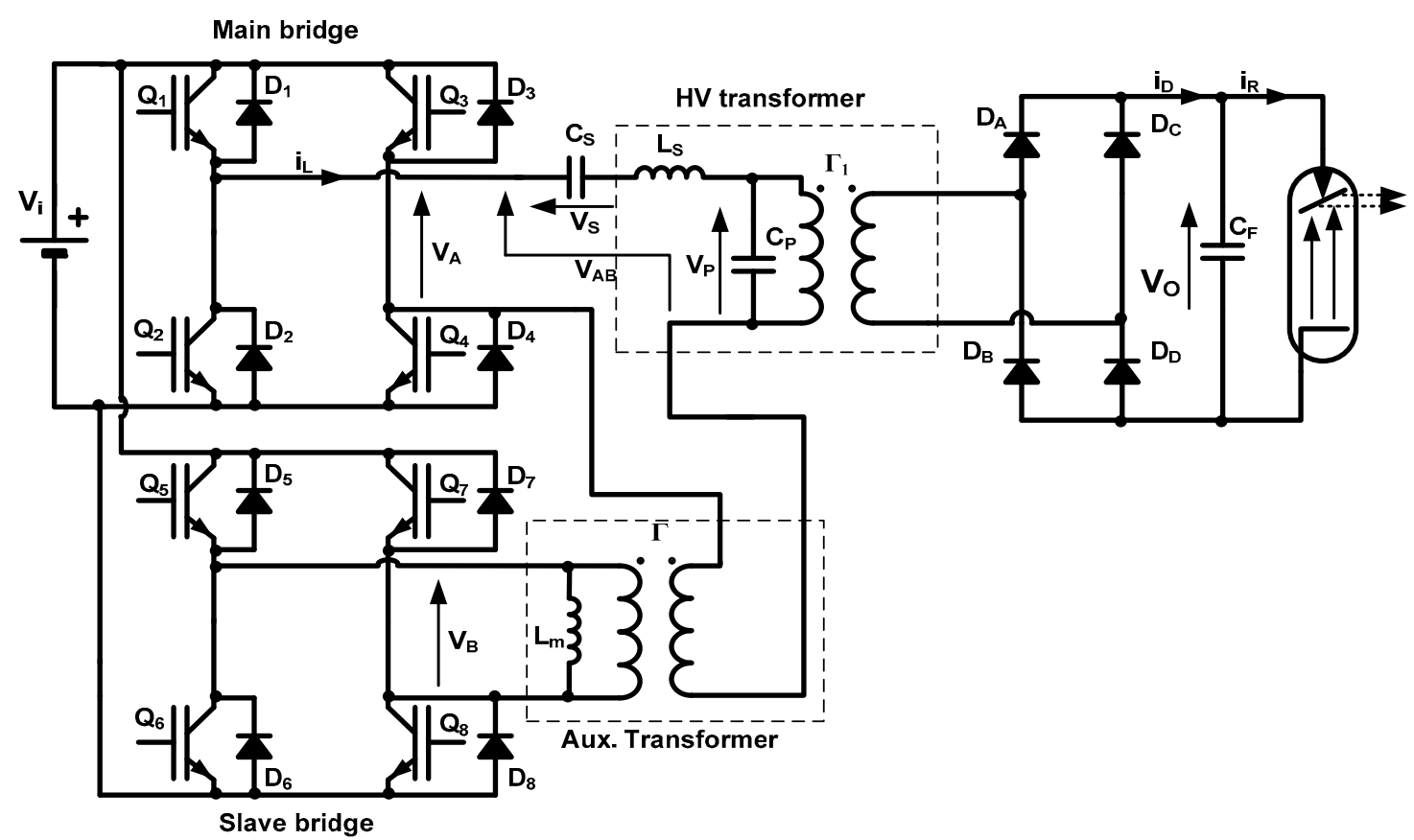

Figure 3. Multilevel topology proposed.

The current, handled by the resonant tank, is the same as the one that flows through the main and auxiliary full-bridge converters. Figure 4 shows the voltage and current waveforms at the input of the resonant circuit. The use of two full-bridges increases the number of control variables: the duty cycle of the main bridge, $\tau_{1}$, and that of the slave bridge, $\tau_{2}$.

The multilevel converter proposed in this paper allows two control actions. By changing the duty cycle of the auxiliary bridge, $\tau_{2}$, the first harmonic amplitude of the voltage at the input of the resonant tank, $V_{A B 1}$, is kept constant regardless of any variations in the grid DC voltage, $V_{i}$ (Figure 3 ). For the case considered in this paper, this value is chosen to be $V_{A B 1}=750 \mathrm{~V}$. The other control parameter, $\tau_{1}$, should be used to keep the output voltage constant during the radiography process.

Knowing that the voltage across the resonant tank will always have the same value $\left(V_{A B 1}=750 \mathrm{~V}\right)$ poses a great advantage in the design: all the components of the resonant tank need to be calculated for a single, high-value voltage. If this high-voltage value were not unique, the only way to ensure that the nominal output power demanded by the $\mathrm{X}$-ray tube can be provided would be by designing all of the components for the lowest input voltage $\left(V_{A B 1}=400 \mathrm{~V}\right)$, which always results in a larger parallel capacitor, $C_{P}$, and higher resonant currents according to Expression (1). Consider, for instance, the following typical radioscopy specifications: input voltage: $400-750 \mathrm{~V}$, output voltage $V_{O}=50-150 \mathrm{kV}$, output power $P_{O}=100 \mathrm{~kW}$, lower frequency $f_{c m i n}=50 \mathrm{kHz}$; the resonant current obtained with a traditional design, where the voltage considered at the input of the resonant tank must be $400 \mathrm{~V}$, can be compared to that obtained in a converter where this voltage is set to $750 \mathrm{~V}$, thanks to $\tau_{2}$ allowing input voltage control (Figure 4).

As stated above, when a traditional design is considered (Figure 2), the lowest input voltage must be used to calculate the resonant elements $[9,10]$ in order to guarantee that the maximum output power can be achieved for any value of the input voltage.

$$
L_{S}=\frac{1}{\left(2 \cdot \pi \cdot f c_{\min }\right)^{2} \cdot C_{S}}
$$




$$
\begin{gathered}
C=L_{S} \cdot\left[\frac{P_{O \max }}{K_{\alpha} \cdot V i^{2}{ }_{\min }}\right]^{2} \\
C=\frac{C_{S} \cdot C_{P}}{C_{S}+C_{P}}
\end{gathered}
$$

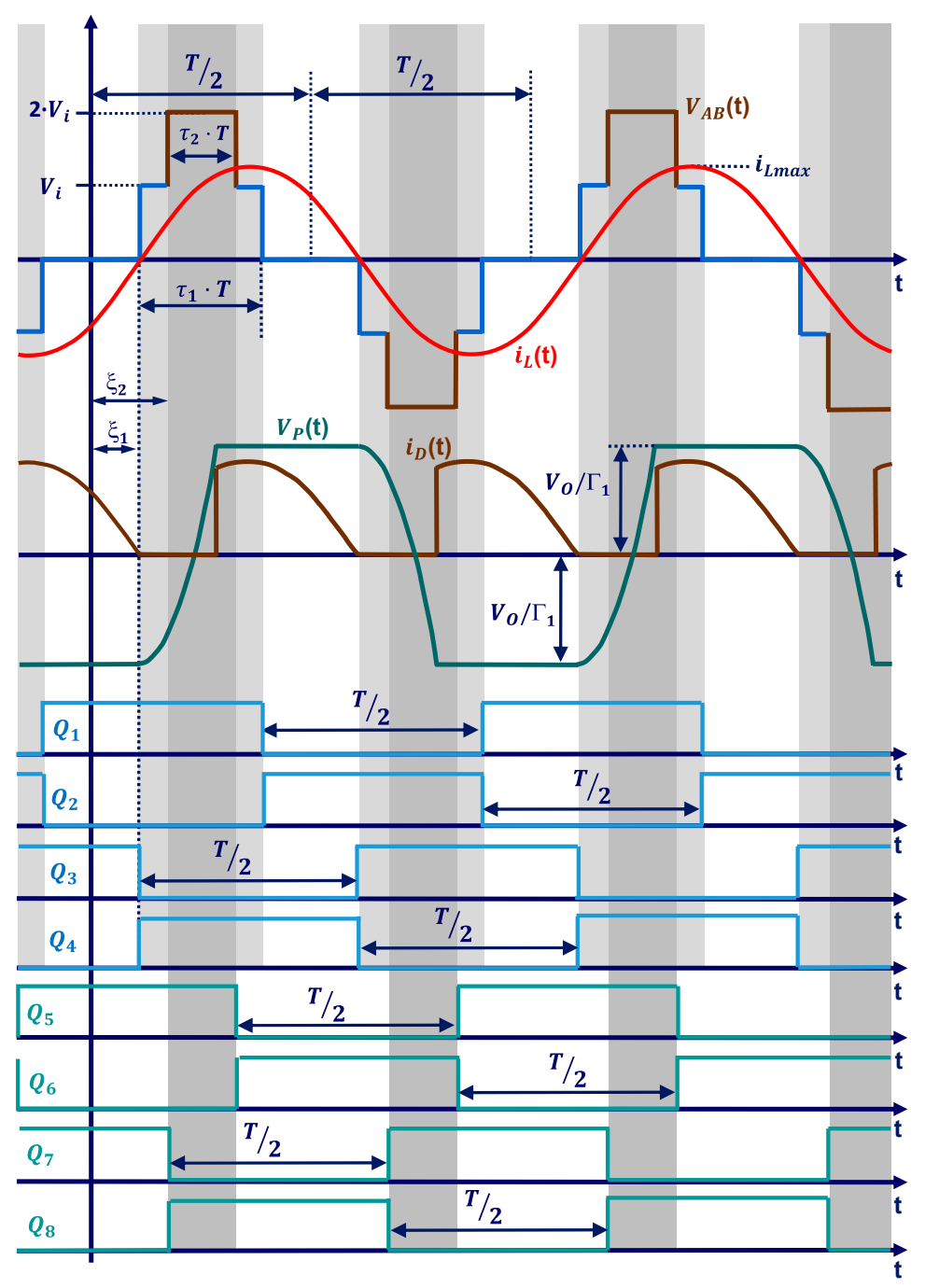

Figure 4. Voltage $\left(V_{A B}\right)$ and current $\left(i_{L}\right)$ at the input of the resonant tank. $\xi_{1}, \xi_{2}$ represent the gate delay signals.

Using Equations (2)-(4) above, and considering a minimum operation frequency $f_{c m i n}=50 \mathrm{kHz}$ and a converter conversion ratio $k_{\alpha}=3.4$ (Equation (5), experimentally obtained), the components of the resonant tank in the converter of Figure 2 are calculated to be: $C_{S}=950 \mathrm{nF}, C_{P}=630 \mathrm{nF}$ and $L_{S}=10 \mu \mathrm{H}$.

$$
\begin{gathered}
k_{\alpha}=12.67 \alpha^{2}-21.65 \alpha+11.75 \\
\alpha=\frac{C_{S}}{C_{S}+C_{P}}
\end{gathered}
$$

Considering these values, the current through the series inductor at $f_{c}=75 \mathrm{kHz}$ is $I_{L}=450 \mathrm{~A}$ if $100 \mathrm{~kW}, 125 \mathrm{kV}$ are to be obtained at the output when $V_{i}=400 \mathrm{~V}$ (Figure 5). 


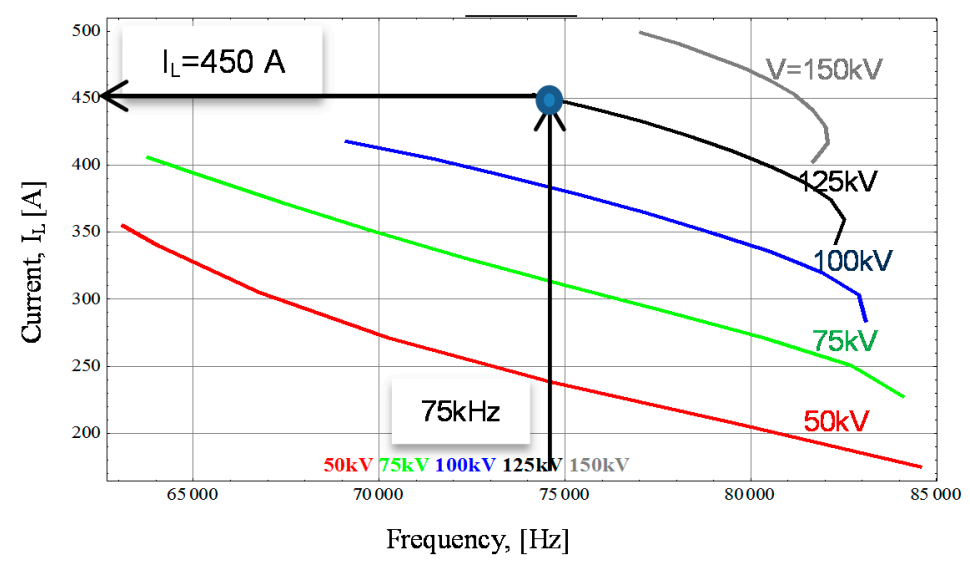

Figure 5. Resonant current $I_{L}$ versus output voltage and switching frequency at $V_{i}=400 \mathrm{~V}$.

However, if a multilevel structure, like the one in Figure 3, is used instead of a traditional converter, the values of the resonant components will be different. Since the first-harmonic amplitude of the voltage across the resonant tank can be considered constant $\left(V_{A B 1}=750 \mathrm{~V}\right.$ for $\left.V_{i}=400 \mathrm{~V}\right)$, the values obtained in this case are: $C_{S}=270 \mathrm{nF}, C_{P}=180 \mathrm{nF}$ and $L_{S}=38 \mu \mathrm{H}$.

Figure 6 evinces that the resonant current in the multilevel structure for the same operating point has been halved due to the inclusion of an additional bridge $\left(I_{L}=228 \mathrm{~A}\right)$ and that the switching frequency is also slightly lower $\left(f_{c}=64 \mathrm{kHz}\right)$.

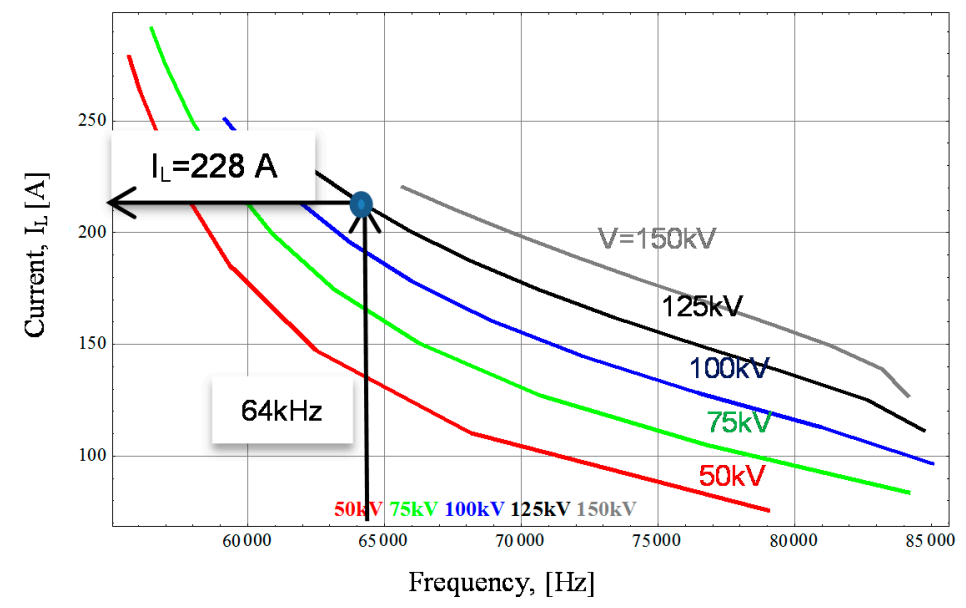

Figure 6. Resonant current $\mathrm{I}_{\mathrm{L}}$ versus output voltage and switching frequency at $V_{\mathrm{i}}=750 \mathrm{~V}$.

This situation was to be expected, since now the same power transferred to the load comes from two full bridges with the same input voltage $\left(V_{i}=400 \mathrm{~V}\right)$; therefore, each one supplies half of the power, which means half of the resonant current. This is so because both duty-cycles, $\tau_{1}$ and $\tau_{2}$, are almost the same to supply the maximum power.

The number of switches in the multilevel converter is doubled, but their specification of maximum current is halved; thus, the final cost does not increase significantly as far as the switches are concerned $[23,24]$. The other important advantage offered by the auxiliary transformer is the capability to modify the resonant tank of the topology depending on the X-ray technique used. If the converter must supply the maximum voltage and power (radioscopy), the two bridges of the topology operate simultaneously, but with a different duty cycle. Since the voltage gain of the multilevel LCC converter depends on several parameters $\left(f_{C}, \tau_{1}, \tau_{2}, R_{O}\right)$, by using normalized values where $V_{X}=V_{O} / V_{i}$, $R=R_{O} / Z_{B}, Z_{B}=\left(L_{S} / C\right)^{0.5}$, some plots can be obtained to observe the boost capability of this converter (Figure 7). 


$$
\begin{gathered}
V_{A B}(t) \approx F_{A B 1 S}\left(\tau_{1}, \tau_{2}, \Gamma, V_{i}\right) \cdot \sin (\omega t)+F_{A B 1 C}\left(\tau_{1}, \tau_{2}, \Gamma, V_{i}\right) \cdot \cos (\omega t) \\
F_{A B 1 S}=\frac{2 V_{i}}{\pi}\left((2+\Gamma) \sin \left(\pi \tau_{1}\right)-\Gamma \sin \left(\pi\left(\tau_{1}-2 \tau_{2}\right)\right)\right) \\
F_{A B 1 C}=-\frac{2 \Gamma V_{i}}{\pi}\left(\cos \left(\pi \tau_{1}\right)+\cos \left(\pi\left(1-\tau_{1}+2 \tau_{2}\right)\right)\right)
\end{gathered}
$$

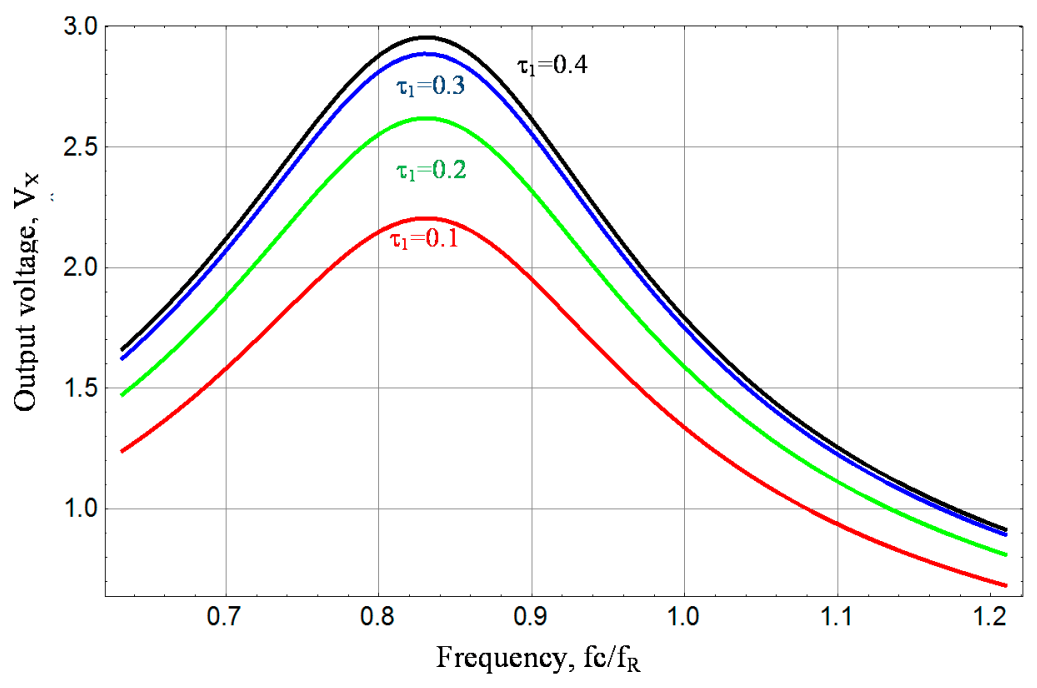

Figure 7. Output voltage versus frequency for $\tau_{2}=0.2$ and $R=1.0$.

From the equations above, the first harmonic of the input voltage to the resonant tank can be obtained. This first harmonic can be used to determine the gain of the converter by using the set of equations published in reference [9], which must be solved by using numerical methods. The multilevel converter operation is the same as that of the traditional one, only changing the input voltage to the resonant elements, which is defined by Equation (7).

However, in the fluoroscopy mode, when low output power is required, the slave bridge is turned off and the auxiliary transformer participates in the topology by leaving its magnetizing inductance in series with the resonant inductance (Figure 8). This results in the actual resonant inductor now being $L_{S}+L_{m}$, which reduces the capability of the main bridge to transfer power, as well as the maximum value of the resonant current.

Thus, in radioscopy mode, the resonant inductance is made up by the main transformer leakage inductance only $\left(L_{S}=38 \mu \mathrm{H}\right)$, whereas in fluoroscopy mode, the magnetizing inductance of the auxiliary transformer $\left(L_{m \text {-aux }}=125 \mu \mathrm{H}\right)$ is added to this leakage inductance. In the case of the operation points defined in Table 1, the resonant current is divided by a factor as high as five.

Operation in fluoroscopy mode also evinces a different performance when using a single-full-bridge topology (traditional design, Table 1(A)), and the multilevel topology proposed in this paper when the slave bridge is off (Table 1(B)). These tables show large variations in the resonant current due to the auxiliary transformer. This current reduction, in turn, gives rise to a reduction of conductive losses in the IGBTs (Isolated Gate Bipolar Transistors) (FF300R12KS4). It must be noted that the frequency drop also contributes to reducing the switching losses. Assuming the datasheet values: $E_{O N}=25 \mathrm{~mJ}$ (Turn-on energy loss per pulse) and $E_{O F F}=15 \mathrm{~mJ}$ (Turn-off energy loss per pulse) at $V_{C E}=600 \mathrm{~V}$, $I_{C}=300 \mathrm{~A}$, which results in switching power losses of $\left(E_{O N}+E_{O F F}\right) \cdot f_{C}=3.2 \mathrm{~kW}$; by reducing the current to $60 \mathrm{~A}$, the energy losses are reduced to $E_{O N}=7 \mathrm{~mJ}, E_{O F F}=4 \mathrm{~mJ}$ with $V_{C E}=600 \mathrm{~V}, I_{C}=60 \mathrm{~A}$, which gives rise to $594 \mathrm{~W}$ switching losses only. 


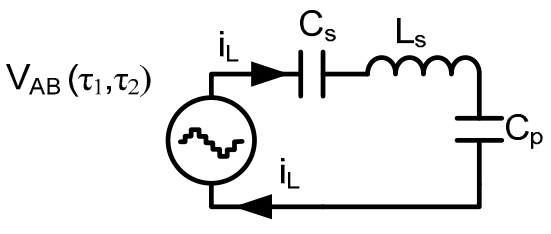

Radioscopy

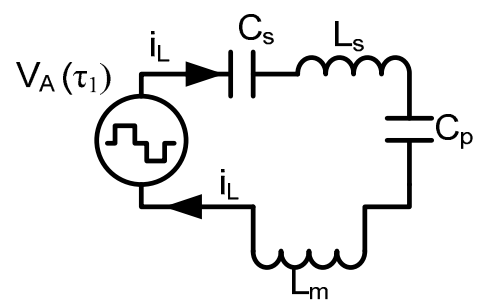

Fluoroscopy

Figure 8. Resonant circuit for radioscopy and fluoroscopy.

Table 1. Design comparison for Fluoroscopy operation. (Output voltage: 120 kV. Output power: $1.2 \mathrm{~kW}$ ).

\begin{tabular}{ccccc}
\hline \multicolumn{5}{c}{ A. Full Bridge. Traditional Design } \\
\hline$V i$ & $V_{O}$ & $P_{O}$ & $I_{L}$ & $f_{\mathcal{C}}$ \\
$400 \mathrm{~V}$ & $120 \mathrm{kV}$ & $1200 \mathrm{~W}$ & $309 \mathrm{~A}$ & $80.5 \mathrm{kHz}$ \\
$750 \mathrm{~V}$ & $120 \mathrm{kV}$ & $1200 \mathrm{~W}$ & $310 \mathrm{~A}$ & $81.1 \mathrm{kHz}$ \\
\hline \multicolumn{5}{c}{ B. Full Bridge. Multilevel Design } \\
\hline $400 \mathrm{~V}$ & $120 \mathrm{kV}$ & $1200 \mathrm{~W}$ & $60 \mathrm{~A}$ & $53.7 \mathrm{kHz}$ \\
$750 \mathrm{~V}$ & $120 \mathrm{kV}$ & $1200 \mathrm{~W}$ & $61 \mathrm{~A}$ & $54.5 \mathrm{kHz}$ \\
\hline
\end{tabular}

\subsection{High Voltage Transformer}

One of the most critical parts in the design of the high-voltage power supply is the main transformer. This is the component that must guarantee the equipment isolation and raise the output voltage to the values specified by the load $(150 \mathrm{kV})$. The inclusion of a high-voltage transformer has an important effect in the topology operation. Due to the large values of the transformer parasitic elements, they must be included as resonant topology elements. By doing so, the need of additional, bulky reactive elements can be avoided. But parasitic elements can only be calculated before construction if the transformer geometry is accurately characterized [25]; the use of FEA (finite-element-analysis) tool helps designers in this task, making it possible to define the geometry of the transformer, and the materials used for its construction, etc.

To facilitate the transformer parameters calculation and assembly, the secondary winding was built by using two windings of $n=20$ PCB's (printed circuit board) each (Figure 9). Each secondary winding is connected to a rectifier, both of which are externally connected in series to produce the output voltage.

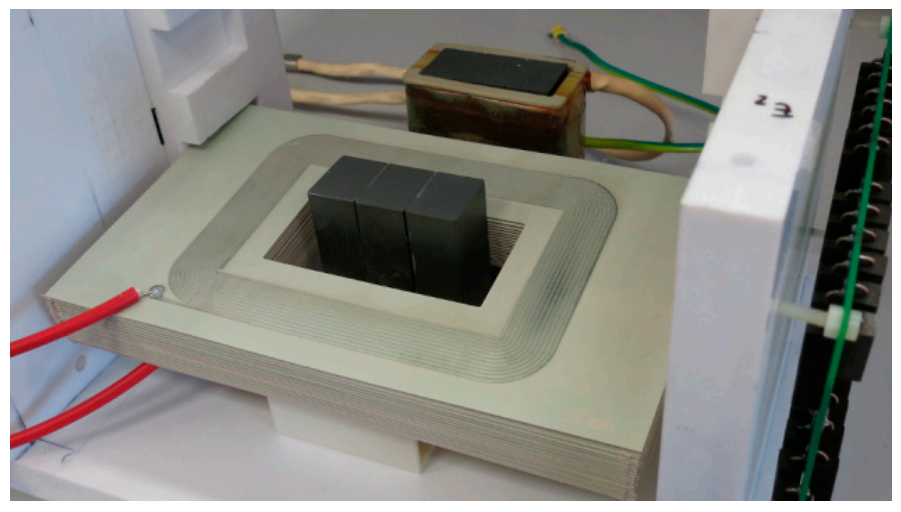

Figure 9. Secondary winding of the high-voltage transformer.

The plastic material used to hold the PCB's is Arnite, which exhibits low $\mathrm{H}_{2} \mathrm{O}$ absorption $(0.1 \%$ D-570 test), dielectric constant at $1 \mathrm{MHz} \varepsilon=3.2$, electrical strength $22 \mathrm{kV} / \mathrm{mm}$, and a good durability in 
industrial oil. The PCB's were manufactured with Arlon material TC-600 (0.5 mm thick) $70 \mu \mathrm{m}$-thick (double layer). This material has very good properties at high frequency (tens of $\mathrm{GHz}$ ): $\varepsilon=6.1$, electrical strength $34 \mathrm{kV} / \mathrm{mm}$, dissipation factor $\mathrm{DF}=0.002$. The transformer was built with two secondary windings of 20 PCB's; each PCB has 12 turns per layer, which means 24 turns/PCB. The maximum voltage between secondary windings is $75 \mathrm{kV}$. The transformer is immersed in oil $(20 \mathrm{kV} / \mathrm{mm})$; therefore, an isolation of $75 \mathrm{kV}$ is guaranteed by a distance between windings of $20 \mathrm{~mm}$. The oil also helps to dissipate heat away from the whole structure. Using these construction parameters, it is possible to calculate the electric and magnetic fields in the structure if information about the currents and the expected voltages are included in the model; hence, the parallel capacitance and the leakage inductance of the transformer can be obtained. The parasitic capacitance of the secondary winding is modeled as several capacitors in series that define the interlayer capacitance, $\mathrm{Ci}$ (Figure 10).

The electric field between two conductive layers (Figure 11), used to represent the tracks on a $\mathrm{PCB}$, depends on the distance to the via that allows for the interconnection between top and bottom layers $(x)$.

$$
E(x)=\frac{\left(\frac{V_{O}}{n}\right) \cdot x}{s \cdot h}
$$

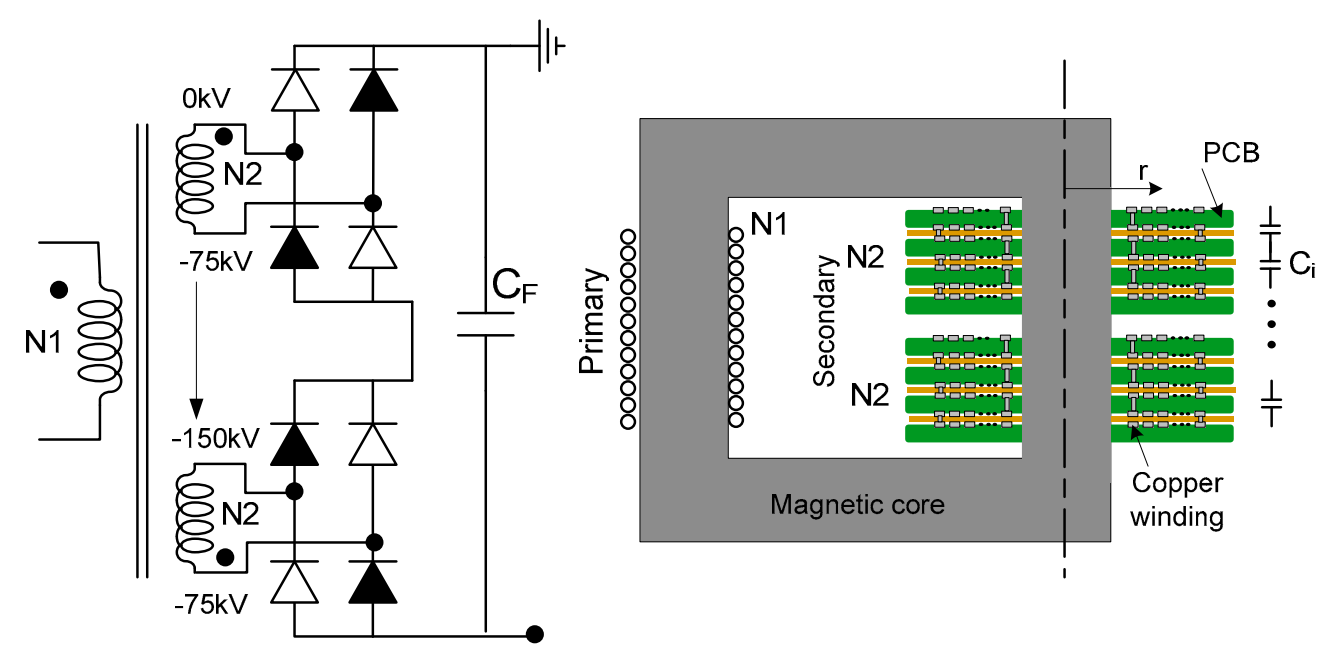

Figure 10. Cross section of the high-voltage transformer and external connection.

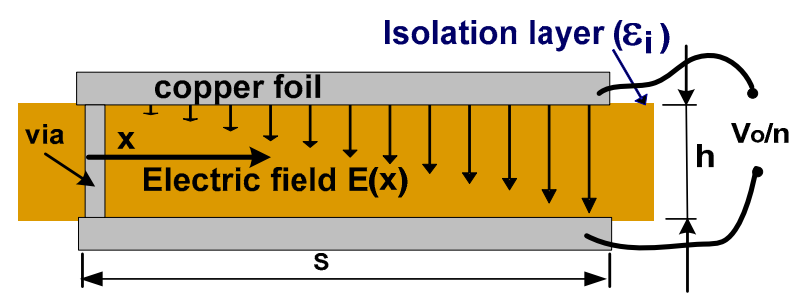

Figure 11. Parasitic capacitance of two conductive layers. Geometrical model of a PCB (printed circuit board).

Using this expression, together with the dielectric constant of the insulation material, $\varepsilon_{i}$, the energy associated to the electric field between two conductive layers can be calculated as follows:

$$
\begin{aligned}
\text { Energ }_{i} & =\frac{1}{2} \cdot \varepsilon_{i} \cdot \int_{v} E_{i}(x)^{2} d v \\
E_{T} & =\sum_{i} \text { Energy }_{i}
\end{aligned}
$$


The total energy $E_{T}$ between all windings, calculated from Equation (12), can be associated to an equivalent capacitor referred to the primary side by using the transformer ratio $\Gamma_{1}$ :

$$
C_{P}=\frac{2 \cdot E_{T}}{V_{O}^{2}} \cdot \Gamma_{1}^{2}
$$

The leakage inductance can be obtained in a similar way; in this case, the leakage magnetic energy (FEA tools) in the windings must be calculated and associated to the series inductance $L_{S}$, assuming the primary current $I$ is known:

$$
\begin{gathered}
E_{\text {mag }}=\frac{\mu \cdot \int H^{2} d v}{2} \\
L_{S}=\frac{\mu \cdot \int H^{2} d v}{I^{2}}
\end{gathered}
$$

All of these equations allow designers to define the geometry of the main transformer that will provide the desired resonant elements $L_{S}$ and $C_{P}$. Thus, the only component that needs to be added externally is the series capacitor, $C_{S}$.

The process for designing the HV transformer starts with the specification of the turn ratio $r t=V_{O} /\left(V_{i} \cdot r_{C}\right)$, where $r_{C}$ is the converter gain (Figure 7), which can vary from 2.5 to 6 in an LCC topology. Assuming a constant input voltage in the multilevel converter, $V_{i}=750 \mathrm{~V}$, and a maximum output voltage $V_{O}=150 \mathrm{kV}$, a turn ratio $r t=80$ was selected. The number of turns in the primary (N1) is a parameter that can be used to control the value of the leakage inductance, $L_{S}$, because this magnitude increases with the square of N1. The parasitic capacitance is calculated by adding the contribution of each PCB; therefore, there are two variables that can be modified to increase $C_{P}$ : "s", and the length of the turns $(" 2 \cdot \pi \cdot r$ " if circular). The advantage of increasing " $s$ " instead of " $r$ " is the associated decrease of the winding resistance. The definition of the final transformer geometry requires several FEA simulations modifying N1, $\mathrm{s}$, and $\mathrm{r}$ until the desired parameters are found. The experimental values obtained from the actual HV transformer were: $L_{S}=38 \mu \mathrm{H}, C_{P}=122 \mathrm{nF}, L m=918 \mathrm{mH}$. To increase the parasitic capacitance in order to obtain the expected resonant values $(220 \mathrm{nF})$ it was necessary to add $20 \mathrm{pF}$ in the secondary side of the HV transformer. The output capacitor $C_{F}$ used is the parasitic capacitance of the cables, which varies from $1.2 \mathrm{nF}$ to $3.6 \mathrm{nF}$. The low output current and the large diode conduction periods allow the use of such a low output filter capacitor: using $C_{F}=1.2 \mathrm{nF}$ results in $2500 \mathrm{~V}$ output voltage ripple at $100 \mathrm{KW}-150 \mathrm{kV}$, which is lower than the typical specification of $3 \%$.

\section{Results and Discussion}

\subsection{Operation in Radioscopy Mode}

In order to validate the effectiveness of the proposed topology, the resonant tank was built by using discrete components $\left(L_{S}=38 \mu \mathrm{H}, C_{P}=220 \mathrm{nF}, C_{S}=330 \mathrm{nF}\right.$ ), so as to get the values defined by Equations (2)-(4) in order to fulfil the output power and voltage specifications. In this way, the output voltage $\left(V_{O}\right)$ is referred to the primary side. Therefore, the output voltage expected in the actual topology, which includes a high-voltage transformer with a turn-ratio $\Gamma_{1}=1: 80$ (Figure 12), will be 80 times the value obtained in the tests. 


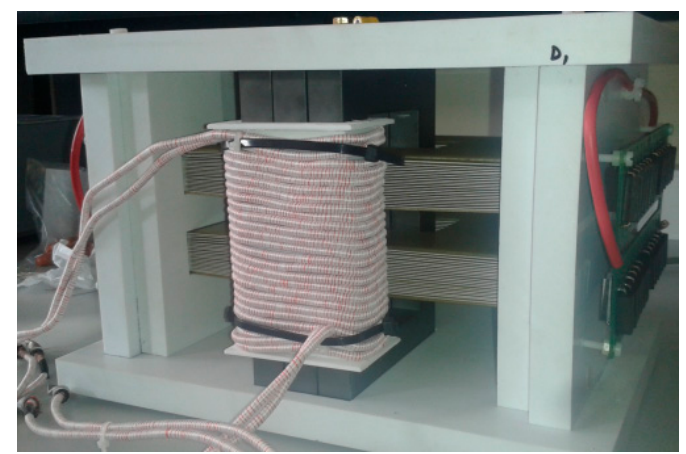

Figure 12. High-voltage transformer.

Nanocrystalline material Vitroperm $500 \mathrm{~F}$ has been used to build the auxiliary transformer in order to avoid saturation. The number of turns in this transformer is $\mathrm{N}_{1} \mathrm{aux}=\mathrm{N} 2_{\mathrm{aux}}=3(\Gamma=1)$.

The two full bridges mounted with IGBTs FF300R12KS4 can be seen in Figure 13. A Texas Instruments DSP (Digital Signal Processor) TMS320F28335 has been used to implement the control of both bridges, and optical fiber has been used to take the control signal from the drivers to the IGBTs.

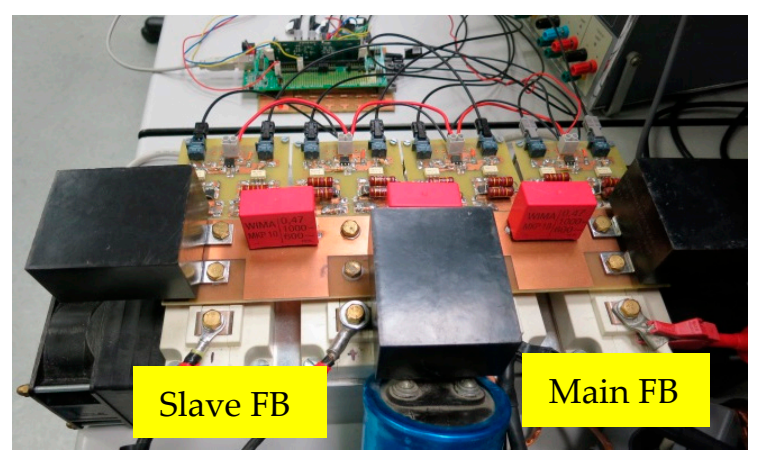

Figure 13. LCC resonant multilevel converter.

The waveforms in Figures 14 and 15 show a radioscopy operating point for both a traditional and a multilevel LCC topology (with both bridges working synchronized in the latter case). The performace of the X-ray tube is represented by a resistive load, $R=88.5 \Omega$. The input voltage simulates the rectified $\mathrm{AC} \operatorname{grid}(\mathrm{Vi}=300 \mathrm{~V})$.

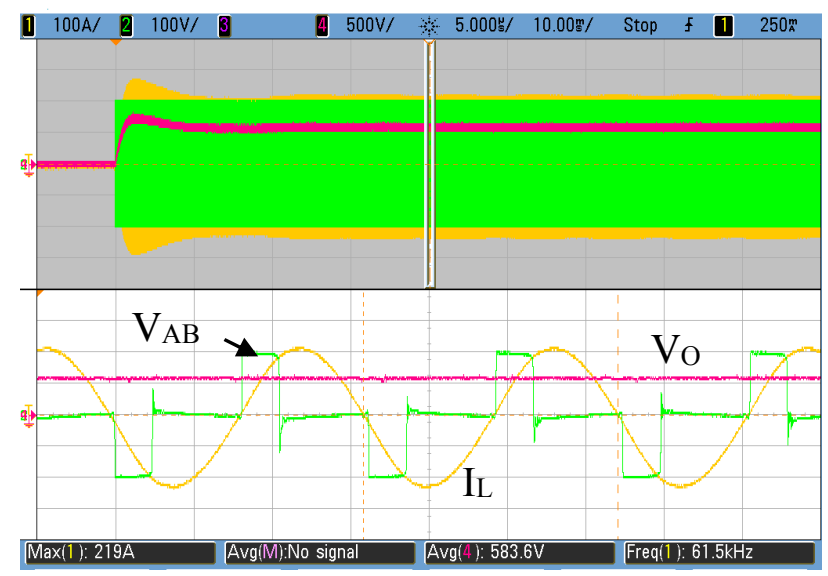

Figure 14. Evolution of voltage $V_{A B}[100 \mathrm{~V} / \mathrm{div}]$ output voltage $V_{O}[500 \mathrm{~V} / \mathrm{div}]$ and current $I_{L}$ $[100 \mathrm{~A} / \mathrm{div}]$ in the traditional LCC converter with a load $R_{O}=88.5 \Omega, P_{O}=3.8 \mathrm{~kW}$. 


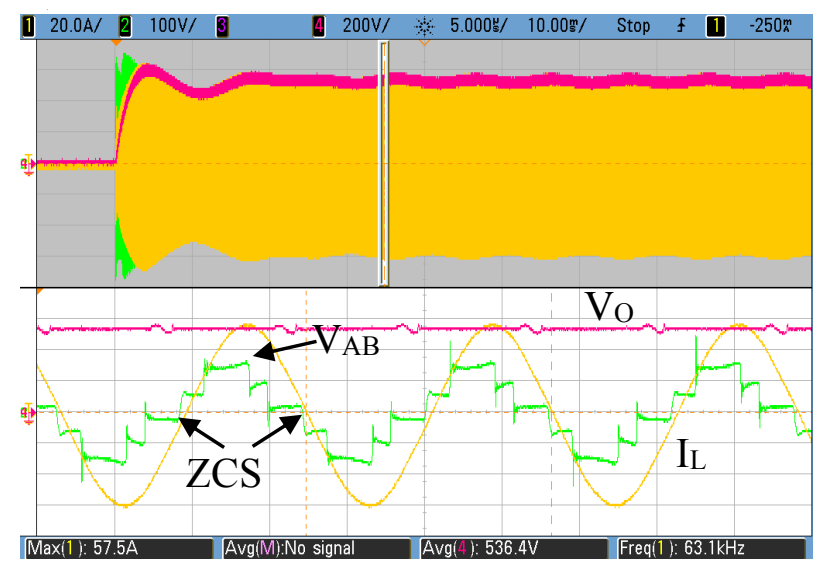

Figure 15. Evolution of voltage $V_{A B}[100 \mathrm{~V} / \mathrm{div}]$ output voltage $V_{O}[200 \mathrm{~V} /$ div $]$ and current $I_{L}$ $[20 \mathrm{~A} / \mathrm{div}]$ in the multilevel LCC converter with a load $R_{O}=88.5 \Omega, P_{O}=3.6 \mathrm{~kW}$.

All of the resonant elements designed for the application were built as discrete components to simulate the HV transformer, thus referring to all of the voltages and currents to the primary side. In the case of the traditional LCC converter, the resonant tank required is: $C_{S}=950 \mathrm{nF}, C_{P}=630 \mathrm{nF}$, $L_{S}=10 \mu \mathrm{H}$ (Table 2), while in the multilevel LCC converter these parameters are replaced by $C_{S}=330 \mathrm{nF}$, $C_{P}=220 \mathrm{nF}$ and $L_{S}=38 \mu \mathrm{H}$.

Table 2. Design parameters for traditional and multilevel LCC converter.

\begin{tabular}{|c|c|c|c|c|}
\hline \multicolumn{5}{|c|}{ A. Full Bridge. Traditional Design (Radioscopy and Fluoroscopy) } \\
\hline Cs & $C_{P}$ & Ls & $\Gamma_{1}$ & fcmin \\
\hline $950 \mathrm{nF}$ & $630 \mathrm{nF}$ & $10 \mu \mathrm{H}$ & 80 & $50 \mathrm{kHz}$ \\
\hline \multicolumn{5}{|c|}{ B. Full Bridge. Multilevel Design (Radioscopy) } \\
\hline Cs & $C_{P}$ & Ls & $\Gamma_{1}$ & fcmin \\
\hline $330 \mathrm{nF}$ & $220 \mathrm{nF}$ & $38 \mu \mathrm{H}$ & 80 & $50 \mathrm{kHz}$ \\
\hline \multicolumn{5}{|c|}{ B. Full Bridge. Multilevel Design (Fluoroscopy) } \\
\hline $330 \mathrm{nF}$ & $220 \mathrm{nF}$ & $163 \mu \mathrm{H}$ & 80 & $50 \mathrm{kHz}$ \\
\hline
\end{tabular}

The significant difference obtained in the value of the resonant current when comparing the traditional and the multilevel LCC converter determines the great advantage of using the proposed stage.

Both Figures 14 and 15, show a similar operation point with $V_{O} \approx 500 \mathrm{~V}$, but the resonant current in the multilevel converter is reduced by a factor of 3.5 as compared to the traditional design. The multilevel converter can be controlled by changing the auxiliary duty cycle $\tau_{2}$ to keep the amplitude of the first harmonic at the resonant tank $V_{A B 1}$ constant, in order to deal with AC grid variations. The duty-cycle $\tau_{1}$ will also help to control the output power. On the other hand, the multilevel voltage $V_{A B}$ has a lower harmonic content when compared with the traditional full-bridge topology, thus reducing EMC (electromagnetic compatibility) problems. Soft switching ZCS (zero-current switching) appears during the turn-on of Q1 and Q2 by controlling the signals supplied to the driver: when the zero current crossing is detected, these switches are activated. The turn-on of Q3 and Q4 takes place with ZVS (zero-voltage switching) because the diodes in parallel start the current conduction before their activation. This ZVS situation also appears in the auxiliary bridge in the radioscopy mode. 


\subsection{Operation in Fluoroscopy Mode}

One of the main advantages of the multilevel converter proposed is that it succeeds in joining, in the same topology, two different types of operation (fluoroscopy and radioscopy) that have been typically solved with two converters independently designed for each case. The resonant elements in the traditional LCC converter are kept the same, but in the multilevel converter the slave bridge is disconnected to include the magnetizing inductance of the auxiliary transformer in the resonant tank. Therefore, the new resonant inductance is $L_{S}=163 \mu \mathrm{H}\left(C_{S}=330 \mathrm{nF}, C_{P}=220 \mathrm{nF}\right)$. The most representative waveforms, referred to as the primary side, are provided for each type of converter.

The multilevel converter one more time exhibits a low amplitude resonant current, while reducing the switching frequency to $41 \mathrm{kHz}$ (Figure 16), whereas it can be seen that the efficiency of the traditional full bridge LCC topology drops when operating in the fluoroscopy mode. It must be noted that in the traditional LCC topology there is no additional $L_{m}$, and a series inductance $L_{S}=10 \mu \mathrm{H}$ is used instead. The capacitors $C s$ and $C_{P}$ are selected to transfer the maximum power $(100 \mathrm{~kW})$ with the minimum input voltage.

Since the traditional LCC converter is designed for high power operation, its frequency should be increased ( $>60 \mathrm{kHz})$ when the power demanded is very low (fluoroscopy) in order to control the output power. Under these conditions, the converter has to manage high reactive power at a higher frequency, as can be noticed from the high resonant current and the low duty-cycle (Figure 17).

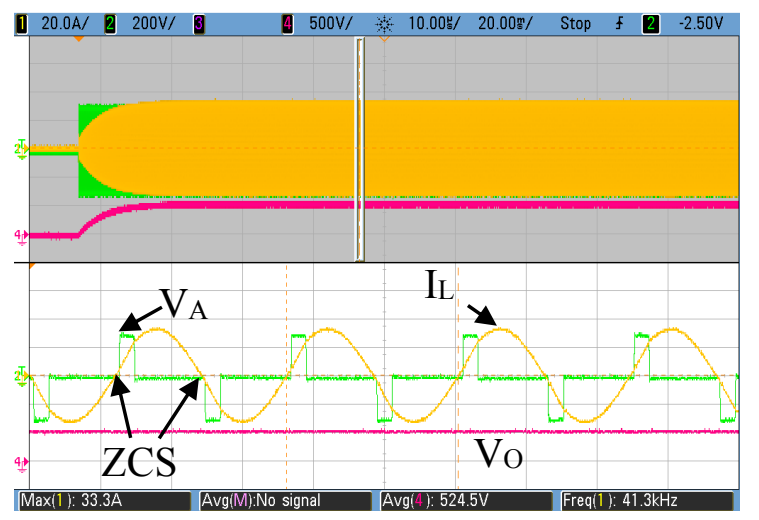

Figure 16. Evolution of voltage $V_{A}\left[200 \mathrm{~V} /\right.$ div] and current $I_{L}[20 \mathrm{~A} /$ div] in the multilevel LCC converter with a load $R_{O}=586 \Omega, P_{O}=470 \mathrm{~W}, V_{i}=300 \mathrm{~V}$ (Fluoroscopy operation).

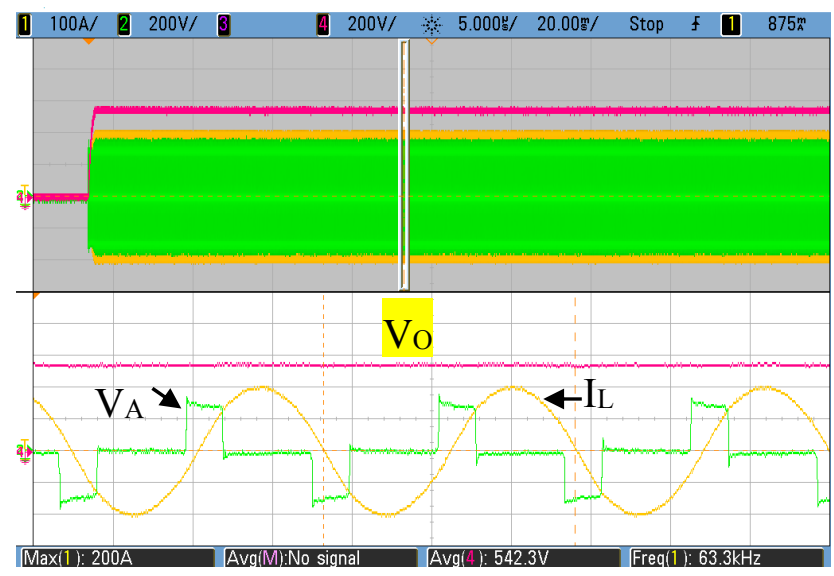

Figure 17. Evolution of voltage $V_{A}[200 \mathrm{~V} / \mathrm{div}]$ and current $I_{L}[100 \mathrm{~A} / \mathrm{div}]$ in the traditional LCC converter with a load $R_{O}=586 \Omega, P_{O}=500 \mathrm{~W}, V_{i}=300 \mathrm{~V}$ (Fluoroscopy operation). 
Therefore, in the multilevel converter the amplitude of the resonant current has been highly reduced, thus power losses are improved thanks to both effects: low switching frequency and low resonant current amplitude. The efficiency in fluoroscopy mode for the traditional (Trad) and multilevel (Mult) converter has been measured at different loads $\left(R_{O}=586,1175,1880 \Omega\right)$, Figure 18. The output voltage is referred to as the primary side $\left(\Gamma_{1}=1: 80\right)$. The input voltage was fixed to $300 \mathrm{~V}$. With this operation mode the output power is typically lower than $1.2 \mathrm{~kW}$. The traditional LCC converter is penalized by the low output power demanded, since it must be designed for the maximum output power specified. The efficiency in radioscopy mode was also analyzed (Figure 19). During the experimentation, the maximum power delivered was $6 \mathrm{~kW}$, which means $10 \mathrm{~kW}$ at the input of the traditional LCC converter. Again, the important resonant current reduction allows for a higher efficiency to be obtained in the multilevel converter.

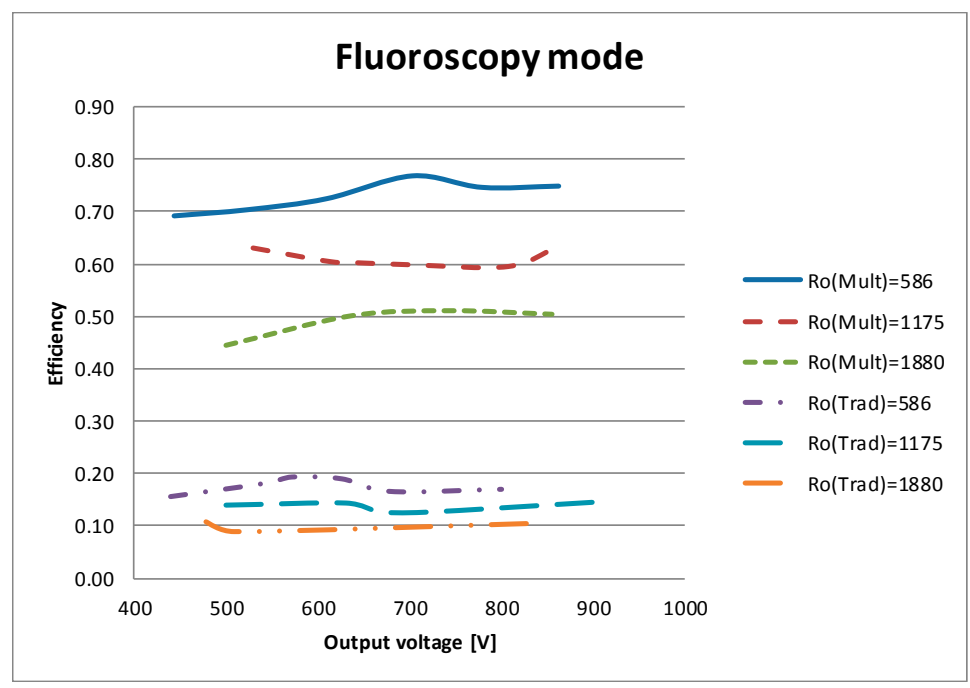

Figure 18. Efficiency during fluoroscopy operation for different loads and output voltage (referred to the primary side) by using the traditional LCC (Trad) or the multilevel LCC (Multi).

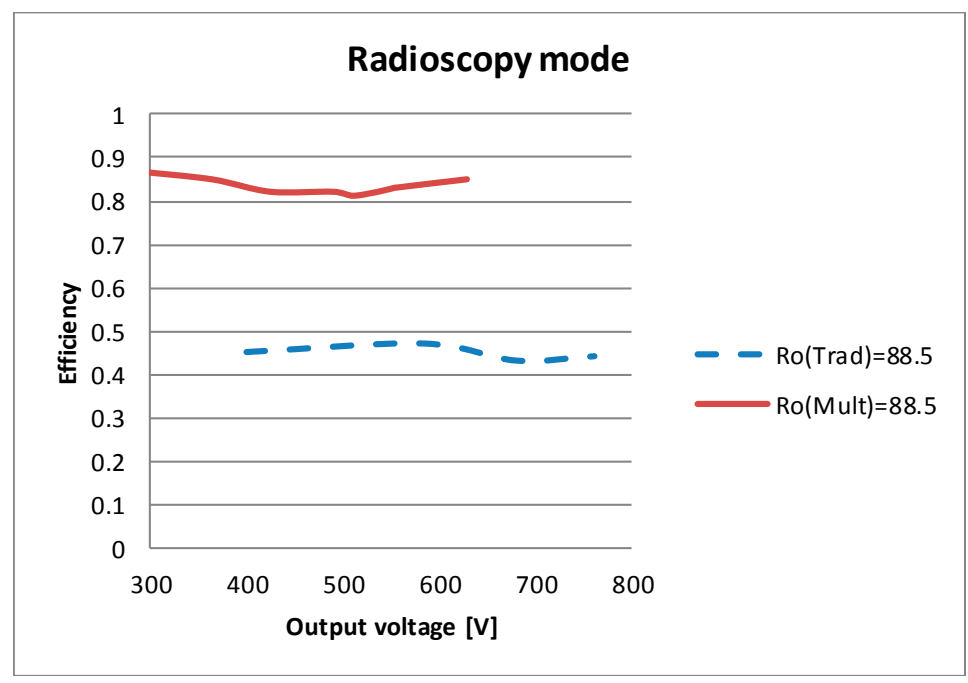

Figure 19. Efficiency during radioscopy operation for different loads and output voltage (referred to the primary side) using the traditional LCC or the multilevel LCC. 


\section{Conclusions}

The design of power supplies for high-voltage applications is conditioned by the wide range of input power and voltage required. This situation is especially complex in X-ray generations, where specifications define power ranges from hundreds of watts to hundreds of $\mathrm{kW}$, but it also appears in other applications such as electron beam welding or electrostatic precipitators.

Traditional LCC Full Bridge converters are typically designed for high-power operation (radioscopy), while low-power situations (fluoroscopy) are solved by increasing the switching frequency and the reactive power. The resonant current cannot be reduced because it is defined by the output voltage and the value of the resonant capacitor, $C_{P}$. On the other hand, the increase of the switching frequency and output power cannot always be achieved, due to semiconductors limitations.

In this work, a multilevel LCC resonant converter is proposed that includes two full-bridge topologies operating in parallel with different duty cycles. This allows the voltage at the input of the resonant tank to be kept constant, $V_{A B}=750 \mathrm{~V}$, which avoids the need to design the resonant elements for the minimum input voltage specified, $V i=400 \mathrm{~V}$.

Additionally, it is possible to significantly reduce the output power (fluoroscopy mode) by disconnecting the slave bridge. This result in the magnetizing inductance of the auxiliary transformer being added to the resonant circuit, and thus, switching frequency, resonant currents, and the reactive power being substantially reduced.

The final conclusion is that a multilevel topology has been proposed to replace traditional LCC resonant converters in $\mathrm{X}$-ray power supplies. The topology proposed succeeds in reducing the resonant current for any of the operating modes used in these applications. This reduction results in an increased efficiency being obtained with simple modifications: including an additional bridge (whose IGBTs only need to conduct currents half the value of those in the main bridge) and a low-voltage 1:1 transformer that must handle the whole current of the converter.

Acknowledgments: This work has been co-funded by the Plan of Science, Technology and Innovation of the Principality of Asturias through Project FC-15-GRUPIN14-122, and by the Spanish Government with the action TEC2014-53324-R.

Author Contributions: This paper is part of a research carried out by A. M. Pernía and Juan A. Martín-Ramos, whereas Juan Díaz, Miguel J. Prieto and Pedro J. Villegas assisted with FEA and mathematical simulations.

Conflicts of Interest: The authors declare no conflict of interest.

\section{References}

1. Villegas, P.J.; Díaz, J.; Pernía, A.M.; Martínez, J.A.; Nuño, F.; Prieto, M.J. Filament Power Supply for Electron Beam Welding Machine. IEEE Trans. Ind. Electron. 2015, 62, 1421-1429. [CrossRef]

2. Steigerwald, R.L. A comparison of half-bridge resonant converter topologies. IEEE Trans. Ind. Electron. 1988, 3, 174-182. [CrossRef]

3. Sun, J.M.; Wang, S.P.; Nishimura, T.; Nakaoka, M. Resonant mode PWM DC-DC converter with a high-voltage transformer link and its control methods for medical-use X-ray power supply. In Proceedings of the European Power Electronics EPE’99, Lausanne, Switzerland, 7 September 1999.

4. Van der Broek, H.; Rexhausen, W.; Wagner, B.; Geerkens, N. Power Supply Unit Including a PWM Inverter, Notably for an X-ray Generator. U.S. Patent 6,072,856, 6 June 2000.

5. Jeong, B.H.; Cho, J.S.; Mok, H.S.; Choe, G.-H. A novel pulse power supply for magnetron using high voltage capacitor embedded high frequency transformer. In Proceedings of the Nineteenth Annual IEEE Applied Power Electronics Conference and Exposition (APEC), Anaheim, CA, USA, 22-26 February 2004; pp. 1819-1824.

6. Casanueva, R.; Brañas, C.; Azcondo, F.J.; Díaz, F.J. Teaching resonant converters: Properties and applications for variable loads. IEEE Trans. Ind. Electron. 2010, 57, 3355-3363. [CrossRef]

7. Shafiei, N.; Pahlevaninezhad, M.; Farzanehfard, H.; Bakhshai, A.; Jain, P. Analysis of a Fifth-Order Resonant Converter for High-Voltage DC Power Supplies. IEEE Trans. Power Electron. 2013, 28, 85-100. [CrossRef] 
8. Hsu, W.C.; Chen, J.F.; Hsieh, Y.P.; Wu, Y.M. Design and Steady-State Analysis of Parallel Resonant DC-DC Converter for High-Voltage Power Generator. IEEE Trans. Power Electron. 2017, 32, 957-966. [CrossRef]

9. Ramos, J.M.; Diaz, J.; Pernía, A.M.; Nuño, F.; Lopera, J.M. Dynamic and steady-state models for the PRC-LCC resonant topology with a capacitor as output filter. IEEE Trans. Ind. Electron. 2007, 54, 2262-2275. [CrossRef]

10. Bhat, A.K.S. Analysis and design of a series-parallel resonant converter with capacitive output filter. IEEE Trans. Ind. Appl. 1991, 27, 523-530. [CrossRef]

11. Yang, R.; Ding, H.; Xu, Y.; Yao, L.; Xiang, Y. An Analytical Steady-State Model of LCC type Series-Parallel Resonant Converter with Capacitive Output Filter. IEEE Trans. Power Electron. 2014, 29, 328-338. [CrossRef]

12. Diaz, J.; Jose, P.; Saiz, V.; Martin-Ramos, J.A.; Martin-Pernía, A.; Martinez, J.A. A High-Voltage AC/DC Resonant Converter Based on PRC with Single Capacitor as an Output Filter. IEEE Trans. Ind. Appl. 2010, 46, 2134-2142. [CrossRef]

13. Martin-Ramos, J.A.; Villegas Saiz, P.J.; Pernía, A.M. Optimal Control of a High-Voltage Power Supply Based on the PRC-LCC Topology with a Capacitor as Output Filter. IEEE Trans. Ind. Appl. 2013, 49, 2323-2329. [CrossRef]

14. Ivensky, G.; Kats, A.; Ben-Yaakov, S. An RC load model of parallel and series-parallel resonant DC-DC converters with capacitive output filter. IEEE Trans. Power Electron. 1999, 14, 515-521. [CrossRef]

15. Takano, H.; Takahashi, J.; Sun, J.M.; Nakaoka, M. Comparative study of resonant and non-resonant DC-DC converter with parasitic LC components of high-voltage transformer. In Proceedings of the IEEE Industry Applications Society 33rd Annual Meeting (IAS), St. Louis, MO, USA, 12-15 October 1998; pp. 1580-1587.

16. Kim, D.-K.; Moon, S.; Yeon, C.O.; Moon, G.-W. High Efficiency LLC Resonant Converter with High Voltage Gain Using Auxiliary LC Resonant Circuit. IEEE Trans. Power Electron. 2016, 31, 6901-6909. [CrossRef]

17. Martin-Ramos, J.; Pernía, A.M.; Diaz, J.; Nuño, F.; Martínez, J.A. Power supply for a high voltage application. IEEE Trans. Power Electron. 2008, 23, 1608-1619. [CrossRef]

18. Du, Y.; Wang, J.; Wang, G.; Huang, A.Q. Modeling of the High-Frequency Rectifier With 10-kV SiC JBS Diodes in High-Voltage Series Resonant Type DC-DC Converters. IEEE Trans. Power Electron. 2014, 29, 4288-4300. [CrossRef]

19. Cavalcante, F.S.; Kolar, J.W. Small signal model of a $5 \mathrm{~kW}$ high-output voltage capacitive-loaded series-parallel resonant DC-DC converter. In Proceedings of the IEEE Power Electronics Specialists Conference PESC, Recife, Brazil, 16 June 2005; pp. 1271-1277.

20. Wang, B.; Xin, X.; Wu, S.; Wu, H.; Ying, J. Analysis and Implementation of LLC Burst Mode for Light Load Efficiency Improvement. In Proceedings of the IEEE 2009 Applied Power Electronics Conference and Exposition, Washington, DC, USA, 15-19 February 2009; pp. 58-64.

21. Feng, W.; Lee, F.C.; Mattavelli, P.; Huang, D.; Prasantanakorn, C. LLC Resonant Converter Burst Mode Control with Constant Burst Time and Optimal Switching Pattern. In Proceedings of the Applied Power Electronics Conference and Exposition (APEC), Fort Worth, TX, USA, 6-11 March 2011.

22. Martín-Ramos, J.A.; Pardo-Vaquero, O.; Villegas, P.J.; Martínez, J.A.; Pernía, A.M. Multilevel PRC-LCC resonant converter for X-ray generation. Electron. Lett. 2015, 51, 1189-1191. [CrossRef]

23. Debnath, S.; Qin, J.; Bahrani, B.; Saeedifard, M.; Barbosa, P. Operation, Control, and Applications of the Modular Multilevel Converter: A Review. IEEE Trans. Power Electron. 2015, 30, 37-53. [CrossRef]

24. Zeng, R.; Xu, L.; Yao, L.; Williams, B.W. Design and Operation of a Hybrid Modular Multilevel Converter. IEEE Trans. Power Electron. 2015, 30, 1137-1146. [CrossRef]

25. Pernía, A.M.; Lopera, J.M.; Nuño, F. 1D/2D transformer electric model for simulation in power converters. In Proceedings of the IEEE Power Electronic Specialist Conference PESC'95, Atlanta, GA, USA, 18-22 June 1995; Volume 2, pp. 1043-1049.

(C) 2017 by the authors. Licensee MDPI, Basel, Switzerland. This article is an open access article distributed under the terms and conditions of the Creative Commons Attribution (CC BY) license (http:/ / creativecommons.org/licenses/by/4.0/). 